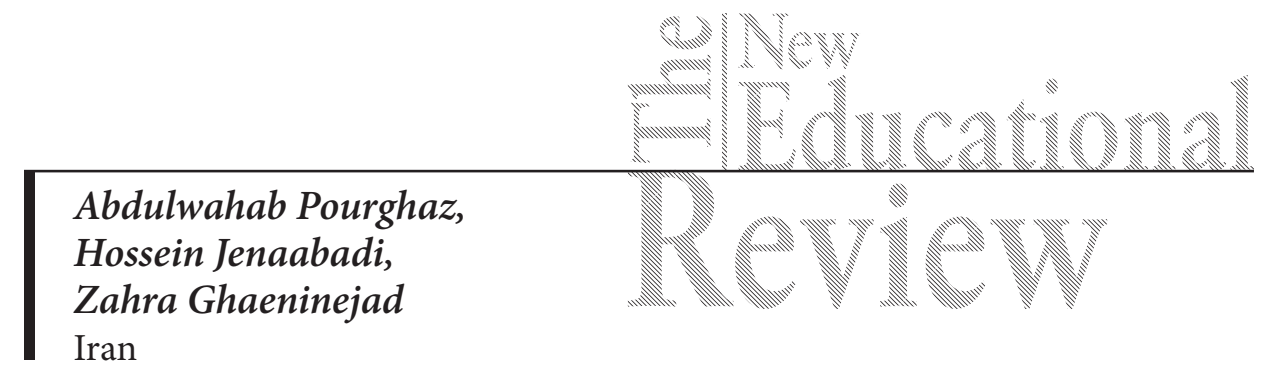

\title{
Personality Types and Sense of Humor and Their Association with Teachers' Performance Improvement
}

DOI: 10.15804/tner.2016.46.4.21

\begin{abstract}
This study aimed to examine the relationship between personality types and sense of humor and their association with teachers' performance improvement. This descriptive study followed a correlational design. Based on Morgan's table, a corpus of 201 elementary school teachers in Nehbandan was selected as a sample, using the stratified random sampling method. The data collection tools were the Williams and Anderson Task Performance Scale (1991), the Eysenck Personality Inventory (1975), and the Moghimi and Ramazani Sense of Humor Questionnaire (2001). The results indicated that extraversion was significantly and positively related to the teachers' performance and sense of humor and neuroticism was significantly and negatively correlated with the teachers' performance and sense of humor. Moreover, a significant and positive relationship was found between a sense of humor and the teachers' performance improvement. Furthermore, the results of regression analysis demonstrated that extraversion, neuroticism, and a sense of humor could predict the teachers' performance.
\end{abstract}

Keywords: personality types, sense of humor, performance, teachers. 


\section{Introduction}

Without human organizations, the development and progress of society is hardly possible. Although fulfilling humans' diverse demands is the existential philosophy of most organizations, organizations need professional and efficient human resources in order to be able to realize their predetermined objectives. Therefore, as time goes by, not only the number of various organizations increases, but also people's behaviors, personal traits, and motives become more complex and difficult to understand (Sha'bani Bahar, Amirtash, Mosharraf Javadi, \& Tondnevis, 2004).

In addition, personality traits include sustainable perception patterns, modes of communication, and individuals' attitudes towards themselves and the environment around them. The personality traits present themselves in a wide range of personal and social aspects. Over the years, several personality psychologists have attempted to fully study the personality structure and define and classify the range of individual differences including normal and abnormal traits (Costa \& Mccrae, 1992). Studies conducted to examine these traits have taken relatively different paths and the normal and abnormal traits, with regard to their qualities, have often been considered as two separate systems (Ball, 2005). From ancient times, humor has existed in life and social relations and it seems that it has a long history. Humor is a means of communication that can determine the depth of individuals' emotions, feelings, and beliefs and can indicate people's attitudes towards various issues (Pouladi Reishahri \& Golestane, 2008: 8). Humor is universal and positive and it has been experienced by people who belong to different social and cultural contexts around the world. This refers to a kind of action, speech, writing that leads to amusement and entertainment. Having a sense of humor indicates a stable personality type and distinguishes people from one another. A sense of humor is a significant factor which is realized in various behaviors, experiences, emotions, feedback, and abilities related to entertainment and being able to laugh and to make people laugh (Bahadori Khosroshahi \& Khanjani, 2011).

Martin (2001) considers humor as a part of positive psychology and believes that humor is an inclusive and multidimensional concept which can be defined as differences in behaviors, experiences, emotions, attitudes, and abilities in relation to being amusing or comic. Barsoux (1996) defines humor as a way to make oneself or others up. Kioumars Saberi (Gol-Agha) distinguished humor from libel and stated that humor is like surgery; however, libel is like slaughter. Without having an intention of evaluation or denying libel, it can be considered as a life recess while humor is a way of teaching that is based on noble goals. Humorous writing 
is a social duty. Political humor is a hard slap in the face of a poisoned person, which does not allow him/her to sleep. It is aimed at saving someone's life like the pressure that is applied to a drowned person. This may break his/her ribs; however, it makes his/her lungs active again (Saberi, 1997, as cited in Pouladi Reishahri \& Golestane, 2008). In general, humor is considered as a personality trait and an emotional response. Humor is a human phenomenon which exists in all societies and cultures with different objects and goals and it is mainly based on a particular set of values and norms. Therefore, whether examined cognitively or emotionally, it is a very complex and pervasive issue (Behpazouh, Jahangiri, \& Zahrakar, 2010).

The presented study sought to answer the following question: Are the personality types and sense of humor related to teachers' performance improvement?

\section{Methods}

This descriptive study followed a correlational design. The statistical population of the study included all male and female elementary school teachers in Nehbandan, including 420 individuals (234 female teachers and 186 male teachers). Among them, based on Morgan's table, a sample of 201 teachers was selected using the stratified random sampling method. The measurement tools were as follows.

The Williams and Anderson Task Performance Scale (1991): the scale, developed by William and Anderson, includes 8 items. The items are scored based on a five-point Likert-type scale ranging from 1 (very low) to 5 (very high).

The Eysenck Personality Inventory (1975): the inventory includes 57 items on various behaviors and feelings. It measures the personality types of extraversion and neuroticism, and indicates an individual's percentile rank.

The Ramazani and Moghimi Sense of Humor Questionnaire (2001): the questionnaire includes 13 items. The items are scored based on a five-point Likert-type scale ranging from 1 (never) to 5 (always).

\section{Results}

Is there any relationship between the personality types and the teachers' performance improvement?

To answer this question, the Pearson correlation coefficient was applied, the results of which are presented in Table 1. 
Table 1. Examining the relationship between the personality types and the teachers' performance improvement

\begin{tabular}{cll}
\hline Variable & Extraversion & Neuroticism \\
\hline Performance & $\mathrm{r}=0.515$ & $\mathrm{r}=-0.336$ \\
\cline { 2 - 3 } & $\mathrm{Sig}=0.000$ & $\mathrm{Sig}=0.000$ \\
\hline & $\mathrm{N}=201 \mathrm{P}<0.01$ \\
\hline
\end{tabular}

As presented in Table 1, the results indicate that the Pearson correlation coefficient between the teachers' performance and extraversion is 0.515 , which is significant at the $99 \%$ confidence level. Therefore, there is a significant and positive correlation between the teachers' performance and extraversion $(\mathrm{P}<0.01)$. Moreover, the Pearson correlation coefficient between the teachers' performance and neuroticism is -0.336 , which is significant at the $99 \%$ confidence level. Therefore, there is a significant and negative correlation between the teachers' performance and neuroticism $(\mathrm{P}<0.01)$. Accordingly, it can be stated that the more extrovert the teacher is, the better performance he/she has and the more neurotic the teacher is, the less performance he/she shows.

\section{Is there any relationship between a sense of humor and the teachers' performance improvement?}

To answer this question, the Pearson correlation coefficient was applied, the results of which are presented in Table 2 .

Table 2. Examining the relationship between a sense of humor and the teachers' performance improvement

\begin{tabular}{cll}
\hline Variable & \multicolumn{2}{c}{ Sense of humor } \\
\hline Performance & $\mathrm{R}$ & \multicolumn{1}{c}{ Sig } \\
\cline { 2 - 3 } & 0.687 & 0.000 \\
\hline \multicolumn{3}{c}{$\mathrm{N}=201 \mathrm{P}<0.01$} \\
\hline
\end{tabular}

As Table 2 demonstrates, the results show that the Pearson correlation coefficient between the teachers' performance and a sense of humor is 0.687 , which is significant at the $99 \%$ confidence level $(\mathrm{P}<0.01)$. Therefore, it can be stated that the teachers with a better sense of humor show better performance. 
Is there any relationship between the personality types and the teachers' sense of humor?

To answer this question, the Pearson correlation coefficient was applied, the results of which are presented in Table 3 .

Table 3. Examining the relationship between the personality types and the teachers' sense of humor

\begin{tabular}{cll}
\hline Variable & \multicolumn{1}{c}{ Extraversion } & Neuroticism \\
\hline Sense of humor & $\mathrm{r}=0.619$ & $\mathrm{r}=-0.151$ \\
\cline { 2 - 3 } & $\mathrm{Sig}=0.000$ & $\mathrm{Sig}=0.032$ \\
\hline & $\mathrm{N}=201 \mathrm{P}<0.01 \mathrm{P}<0.05$ \\
\hline
\end{tabular}

The results presented in Table 3 demonstrate that the Pearson correlation coefficient between the teachers' sense of humor and extraversion is 0.619 , which is significant at the $99 \%$ confidence level. Therefore, there is a significant and positive correlation between the teachers' sense of humor and extraversion $(\mathrm{P}<0.01)$. Moreover, the Pearson correlation coefficient between the teachers' sense of humor and neuroticism is -0.151 , which is significant at the $95 \%$ confidence level. Therefore, there is a significant and negative correlation between the teachers' sense of humor and neuroticism $(\mathrm{P}<0.05)$. Accordingly, it can be stated that the more extrovert the teacher is, the better sense of humor he/she has and the more neurotic the teacher is, the less sense of humor he/she has.

\section{Can the dimensions of personality types predict the teachers' performance improvement?}

To answer this question, the stepwise regression analysis was conducted, the results of which are presented in Table 4.

Table 4. Examining the role of the dimensions of personality types in predicting the teachers' performance

\begin{tabular}{|c|c|c|c|c|c|c|c|c|c|}
\hline & Variables & $\mathrm{R}$ & $\mathrm{R}^{2}$ & Adjusted $\mathrm{R}^{2}$ & $\mathrm{SE}$ & B & $\beta$ & $\mathrm{F}$ & sig \\
\hline \multirow[t]{2}{*}{1} & Extraversion & 0.515 & 0.266 & 0.262 & 4.946 & 0.63 & 0.515 & 71.983 & 0.000 \\
\hline & Extraversion + & & & & & 0.617 & 0.505 & & \\
\hline 2 & Neuroticism & 0.606 & 0.368 & 0.361 & 4.601 & -0.392 & -0.32 & 57.549 & 0.000 \\
\hline \multicolumn{10}{|c|}{$\mathrm{N}=201 \mathrm{P}<0.01$} \\
\hline
\end{tabular}

To investigate the contribution of the dimensions of personality types to determining variances in the teachers' performance, the stepwise regression analysis 
was made. The results show that extraversion and neuroticism are respectively entered into the equation in the first and second steps. As mentioned in Table 4, in the first step, extraversion alone can determine $26.2 \%$ of the variance in the teachers' performance; however, in the second step, extraversion and neuroticism together determine $36.1 \%$ of the variance in the teachers' performance. The results of the standard beta coefficient reveal that, in the regression model, extraversion with a beta coefficient of 0.505 and neuroticism with a beta coefficient of -0.32 are significant at the $99 \%$ confidence level $(\mathrm{P}<0.01)$.

Can a sense of humor predict the teachers' performance improvement?

To answer this question, the simultaneous regression analysis was made, the results of which are presented in Table 5.

Table 5. Examining the role of a sense of humor in predicting the teachers' performance

\begin{tabular}{crrrrrrrr}
\hline Variables & $\mathrm{R}$ & $\mathrm{R}^{2}$ & $\begin{array}{c}\text { Adjusted } \\
\mathbf{R}^{2}\end{array}$ & SE & $\mathbf{B}$ & $\boldsymbol{\beta}$ & $\mathrm{F}$ & Sig \\
\hline Sense of humor & 0.687 & 0.472 & 0.469 & 4.195 & 0.41 & 0.687 & 177.575 & 0.000 \\
\hline $\mathrm{N}=201 \mathrm{P}<0.01$ & & & & & & & & \\
\hline
\end{tabular}

Table 5 shows that a sense of humor can determine $46.9 \%$ of the variance in the teachers' performance. Moreover, the result of the standard beta coefficient reveals that, in the regression model, a sense of humor with a beta coefficient of 0.687 is significant at the $99 \%$ confidence level $(\mathrm{P}<0.01)$.

Is there any significant difference between the teachers' personality types, sense of humor, and performance improvement with regard to their demographic characteristics (gender, years of experience, and level of education)?

To indicate the differences among the teachers' personality types, sense of humor, and performance importance in terms of gender, the independent t-test was used and the one-way analysis of variance was applied to investigate the differences among the teachers' personality types, sense of humor, and performance improvement in terms of years of experience and level of education. The results are presented in the following tables.

The results of the independent t-test conducted to examine the teachers' sense of humor in terms of gender indicate that the calculated $t$, which is equal to 3.725 , with a degree of freedom of 199 is significant at the $99 \%$ confidence level $(\mathrm{P}<0.01)$. 
Table 6. The results of the independent t-test applied to indicate the difference among the teachers' viewpoints in terms of gender

\begin{tabular}{|c|c|c|c|c|c|c|c|}
\hline Variable & Gender & $\mathrm{N}$ & Mean & SD & df & $\mathrm{t}$ & Sig \\
\hline \multirow{2}{*}{$\begin{array}{l}\text { Sense of } \\
\text { humor }\end{array}$} & Male & 88 & 51 & 4.982 & 199 & \multirow[t]{2}{*}{3.725} & \multirow[t]{2}{*}{0.001} \\
\hline & Female & 113 & 46.442 & 11.716 & 199 & & \\
\hline \multirow[t]{2}{*}{ Extraversion } & Male & 88 & 15.034 & 3.633 & 199 & \multirow[t]{2}{*}{4.154} & \multirow[t]{2}{*}{0.000} \\
\hline & Female & 113 & 12.46 & 5.14 & 199 & & \\
\hline \multirow[t]{2}{*}{ Neuroticism } & Male & 88 & 16.34 & 4.782 & 199 & \multirow[t]{2}{*}{-0.47} & \multirow[t]{2}{*}{0.63} \\
\hline & Female & 113 & 16.654 & 4.636 & 199 & & \\
\hline \multirow[t]{2}{*}{ Performance } & Male & 88 & 28.42 & 3.32 & 199 & \multirow[t]{2}{*}{1.213} & \multirow[t]{2}{*}{0.26} \\
\hline & Female & 113 & 27.504 & 7.088 & 199 & & \\
\hline
\end{tabular}

Accordingly, it can be stated that the male and female teachers' attitudes towards having a sense of humor are not the same and the male teachers have a better sense of humor compared to their female counterparts.

Moreover, the results of the independent $\mathrm{t}$-test conducted to examine the personality traits in terms of gender demonstrate that the mean score of the male teachers on extraversion is higher than that of the female teachers. This difference is significant at the $99 \%$ confidence level $(\mathrm{t}=4.154, \mathrm{df}=199, \mathrm{P}<0.01)$; however, no significant difference was found between the male and female teachers in neuroticism at the $95 \%$ confidence level $(t=-0.47, \mathrm{df}=199, \mathrm{P}>0.05)$.

Furthermore, the results of the independent $t$-test carried out to examine the teachers' performance in terms of gender demonstrated in Table 6 show that the calculated t, which is equal to 1.213 , with a degree of freedom of 199 is not significant at the $95 \%$ confidence level $(\mathrm{P}>0.05)$. Therefore, it can be stated that the levels of performance of the male and female school teachers are the same.

The results of the one-way analysis of variance conducted to examine the difference in a sense of humor in terms of years of experience reveal that the calculated $\mathrm{F}$, which is equal to 1.087, is not significant at the $95 \%$ confidence level $(\mathrm{P}>0.05)$. Therefore, considering their years of experience, it can be concluded that the levels of the male and female teachers' sense of humor are the same.

Moreover, the results of the one-way analysis of variance in relation to the difference in extraversion show that the calculated $\mathrm{F}$, which is equal to 3.061, is significant at the $99 \%$ confidence level $(\mathrm{P}<0.01)$. Accordingly, it can be stated that there is a significant difference between the levels of the male and female teachers' extraversion in terms of their years of experience. The teachers with 11 to 20 years 
Table 7. The results of the one-way analysis of variance (ANOVA) conducted to examine the difference among the teachers' viewpoints in terms of their years of experience

\begin{tabular}{|c|c|c|c|c|c|c|c|c|c|c|}
\hline Variable & $\begin{array}{c}\text { Years of } \\
\text { experience }\end{array}$ & $\mathrm{N}$ & Mean & SD & Source & ss & Df & MS & $\mathrm{F}$ & Sig \\
\hline \multirow{3}{*}{$\begin{array}{l}\text { Sense of } \\
\text { humor }\end{array}$} & $1-10$ & 72 & 47.472 & 12.449 & \multirow{2}{*}{ Intragroup } & \multirow{2}{*}{201.616} & \multirow{2}{*}{2} & \multirow{2}{*}{100.808} & \multirow{3}{*}{-1.087} & \multirow{3}{*}{0.33} \\
\hline & $11-20$ & 71 & 49.76 & 5.67 & & & & & & \\
\hline & $21-30$ & 58 & 48.017 & 9.463 & Intergroup & 18359.857 & 198 & 92.727 & & \\
\hline \multirow{3}{*}{$\begin{array}{l}\text { Extra- } \\
\text { version }\end{array}$} & $1-10$ & 72 & 13.722 & 5.227 & \multirow{2}{*}{ - Intragroup } & \multirow{2}{*}{133.079} & \multirow{2}{*}{2} & \multirow{2}{*}{66.539} & \multirow{3}{*}{3.061} & \multirow{3}{*}{0.049} \\
\hline & $11-20$ & 71 & 14.422 & 3.744 & & & & & & \\
\hline & $21-30$ & 58 & 12.396 & 4.923 & Intergroup & 4303.648 & 198 & 21.736 & & \\
\hline \multirow{3}{*}{$\begin{array}{l}\text { Neuroti- } \\
\text { cism }\end{array}$} & $1-10$ & 72 & 177.444 & 5.009 & \multirow{2}{*}{ - Intragroup } & \multirow{2}{*}{120.971} & \multirow{2}{*}{2} & \multirow{2}{*}{60.485} & \multirow{3}{*}{2.797} & \multirow{3}{*}{0.063} \\
\hline & $11-20$ & 71 & 16.394 & 3.863 & & & & & & \\
\hline & $21-30$ & 58 & 15.517 & 5.051 & Intergroup & 4281.218 & 198 & 21.622 & & \\
\hline \multirow{3}{*}{$\begin{array}{l}\text { Perfor- } \\
\text { mance }\end{array}$} & $1-10$ & 72 & 27.347 & 7.269 & \multirow{2}{*}{ Intragroup } & 34.973 & \multirow[t]{2}{*}{2} & \multirow[t]{2}{*}{17.486} & \multirow{3}{*}{-0.525} & \multirow{3}{*}{0.59} \\
\hline & $11-20$ & 71 & 28.225 & 3.622 & & & & & & \\
\hline & $21-30$ & 58 & 28.206 & 5.809 & Intergroup & 6594.231 & 198 & 33.304 & & \\
\hline
\end{tabular}

of experience have the highest mean score and the teachers' with 21 to 30 years of experience have the lowest mean score on extraversion.

Table 8. The results of the Tukey test examining the level of extraversion in terms of the teachers' years of experience

\begin{tabular}{|c|c|c|c|c|}
\hline Variable & Years of experience (I) & \multicolumn{3}{|c|}{ Years of experience (I) Mean Difference (J-I) } \\
\hline \multirow[t]{4}{*}{ Extraversion } & & 1 year- 10 years & $11-20$ years & $21-30$ years \\
\hline & 1 year- 10 years & - & -0.700 & 1.325 \\
\hline & $11-20$ years & - & - & $2.025^{\star}$ \\
\hline & $21-30$ years & - & - & - \\
\hline
\end{tabular}

* significance at the $95 \%$ confidence level

Table 8 shows that only the difference between the teachers with 11-20 years of experience and those with 21-30 years of experience is significant at the $95 \%$ confidence level $(\mathrm{P}<0.05)$. Thus, it can be stated that the more the years of experience of the teacher, the higher his/her extraversion. 
In addition, with regard to the difference in neuroticism in terms of years of experience, the results of the one-way analysis of variance reveal that the calculated $\mathrm{F}$, which is equal to 2.797, is not significant at the $95 \%$ confidence level $(\mathrm{P}>0.05)$. Therefore, in terms of years of experience, it can be stated that the levels of the male and female teachers' neuroticism are the same.

Moreover, as shown in Table 8, the results of the one-way analysis of variance conducted to investigate the difference in the teachers' performance in terms of their years of experience show that the calculated $\mathrm{F}$, which is equal to 0.525 , is not significant at the $95 \%$ confidence level $(\mathrm{P}<0.05)$. Accordingly, it can be stated that the levels of the male and female teachers' performance in terms of their years of experience are the same.

Table 9. The results of the one-way analysis of variance (ANOVA) conducted to examine the difference among the teachers' viewpoints in terms of their level of education

\begin{tabular}{|c|c|c|c|c|c|c|c|c|c|c|}
\hline Variable & $\begin{array}{c}\text { Level of } \\
\text { education }\end{array}$ & $\mathrm{N}$ & Mean & SD & Source & SS & Df & MS & $\mathrm{F}$ & Sig \\
\hline \multirow{3}{*}{$\begin{array}{l}\text { Sense of } \\
\text { humor }\end{array}$} & Associate & 78 & 48.50 & 10.348 & \multirow{2}{*}{ Intragroup } & \multirow{2}{*}{130.014} & \multirow{2}{*}{2} & \multirow{2}{*}{65.007} & \multirow{3}{*}{0.698} & \multirow{3}{*}{0.49} \\
\hline & B.A. & 96 & 47.854 & 9.912 & & & & & & \\
\hline & M.A. & 27 & 50.333 & 5.724 & Intergroup & 18431.458 & 198 & 93.088 & & \\
\hline \multirow{3}{*}{$\begin{array}{l}\text { Extra- } \\
\text { version }\end{array}$} & Associate & 78 & 13.153 & 4.909 & \multirow{2}{*}{ Intragroup } & \multirow{2}{*}{106.564} & \multirow{2}{*}{2} & \multirow{2}{*}{53.282} & \multirow{3}{*}{2.436} & \multirow{3}{*}{0.090} \\
\hline & B.A. & 96 & 13.427 & 4.712 & & & & & & \\
\hline & M.A. & 27 & 12.396 & 4.923 & Intergroup & 4330.162 & 198 & 21.870 & & \\
\hline \multirow{3}{*}{$\begin{array}{l}\text { Neuroti- } \\
\text { cism }\end{array}$} & Associate & 78 & 16.948 & 4.248 & Intragroup & 49.728 & 2 & 24.864 & \multirow{3}{*}{1.131} & \multirow{3}{*}{0.32} \\
\hline & B.A. & 96 & 16 & 4.896 & \multirow{2}{*}{ Intergroup } & \multirow{2}{*}{4352.462} & \multirow[b]{2}{*}{198} & \multirow{2}{*}{21.982} & & \\
\hline & M.A. & 27 & 28.206 & 5.809 & & & & & & \\
\hline \multirow{3}{*}{$\begin{array}{l}\text { Perfor- } \\
\text { mance }\end{array}$} & Associate & 78 & 5.966 & 4.248 & Intragroup & 58.759 & 2 & 29.380 & \multirow{3}{*}{0.885} & \multirow{3}{*}{0.41} \\
\hline & B.A. & 96 & 6.020 & 0.614 & \multirow{2}{*}{ Intergroup } & \multirow[b]{2}{*}{6570.445} & \multirow[b]{2}{*}{198} & \multirow{2}{*}{33.184} & & \\
\hline & M.A. & 27 & 2.856 & 0.742 & & & & & & \\
\hline
\end{tabular}

The results of the one-way analysis of variance performed to examine the difference in a sense of humor in terms of their level of education reveal that the calculated $\mathrm{F}$, which is equal to 0.698 , is not significant at the $95 \%$ confidence level $(\mathrm{P}>0.05)$. Therefore, with regard to their level of education, it can be concluded that the levels of the male and female teachers' sense of humor are the same. 
Moreover, the results of the one-way analysis of variance conducted to assess the difference in extraversion show that the calculated $\mathrm{F}$, which is equal to 2.436 , is not significant at the $95 \%$ confidence level $(\mathrm{P}<0.05)$. Accordingly, it can be stated that the levels of the male and female teachers' extraversion in terms of their level of education are the same.

As Table 9 indicates, the results of the one-way analysis of variance in relation to the difference in the teachers' neuroticism in terms of their level of education reveal that the calculated $\mathrm{F}$, which is equal to 1.131 , is not significant at the $95 \%$ confidence level $(\mathrm{P}>0.05)$. Therefore, with regard to their level of education, it can be stated that the levels of the male and female teachers' neuroticism are the same.

Additionally, with regard to the difference in the teachers' performance in terms of their level of education, the results indicate that the calculated $F$, which is equal to 0.885 , is not significant at the $95 \%$ confidence level $(\mathrm{P}<0.05)$. Accordingly, it can be stated that the levels of the male and female teachers' performance in terms of their level of education are the same.

\section{Discussion and Conclusion}

Since the personality types and sense of humor are among factors affecting teachers' organizational performance, the presented study aimed to examine the relationship among the teachers' personality types, sense of humor, and performance improvement.

The results obtained from the current study demonstrated that the personality types were significantly related to the teachers' performance. The obtained coefficient between these two variables indicated a significant and positive correlation between extraversion and performance and a significant and negative correlation between neuroticism and performance. Therefore, it can be inferred that the teachers who have an extraverted personality type have higher levels of occupational performance compared to those who have a neurotic personality type. These findings are consistent with the results obtained from studies conducted by Khakpour (2004), Sha'bani Bahar et al. (2004), Naderian, Jahromi, and Hosseini (2007), Eliasi (2009), Yazdani (2012), Barrick and Mount (1991), Baron and Greenberg (1993), and Chamorro-Premuzic and Furnham (2003), which indicated a significant relationship between personality types and staff's performance.

Additionally, the results of the present study show a significant and positive relationship between a sense of humor and the teachers' performance improvement, 
i.e., the teachers who have a better sense of humor, compared to other teachers, show higher occupational performance. This finding is in line with the results obtained from a study carried out by Hamidifar (2014), which demonstrated a significant and positive correlation between a sense of humor and staff's performance improvement.

Moreover, the results indicated a significant relationship between the teachers' sense of humor and their personality types, i.e., the teachers' sense of humor was significantly and positively related to extraversion and it was significantly and negatively correlated with neuroticism. This may be due to the fact that extroverts, compared to neurotics, attempt more to gain new experiences and establish more social interactions. Having these social interactions and connections can be a good reason for their happiness and sense of humor. On the other hand, since being a neurotic is accompanied with anxiety, hostility, depression, irritability, unpredictability (Maslach, Schaufeliand, \& Leiter, 2001), neurotics experience lower levels of happiness compared to extroverts. Furthermore, the results of the regression analysis indicated that both personality types, i.e. extraversion and neuroticism, could predict the teachers' performance.

In the present study, a significant difference was found between the male and female teachers in terms of extraversion. The results showed that the male teachers were more extrovert compared to their female counterparts. However, considering neuroticism and performance, no significant difference was observed between the male and female teachers.

Overall, the results obtained from this study reveal that the personality types and sense of humor affect the teachers' organizational performance and create a positive atmosphere for them to do their job. Indeed, being aware of the impacts of the extraverted personality type and sense of humor on teachers' organizational performance can aid principals and authorities to pay more attention to this personality type and create a lively atmosphere in the organization. Creating such an environment not only is effective in creating appropriate behaviors and enhancing employees' effectiveness and dependence, but also, since it promotes their motivation, leads to an increase in the level of efficiency of the organization. In this regard, to increase organizational performance, principals and managers are highly recommended to apply mechanisms that are aimed at improving and promoting the extraverted personality type and creating a lively and cheerful atmosphere. 


\section{References}

Bahadori Khosroshahi, C., \& Khanjani, Z. (2011). The relationship of humor and stressful life events with depression among university students. Zahedan Journal of Research in Medical Sciences, 14 (2), 96-100.

Ball, S.A. (2005). Personality traits, problems, and disorders: Clinical applications to substance use disorders. Proceedings of the Association for Research in Personality, 39(10), 84.102.

Baron, R.A., \& Greenberg, M.S. (1993). Organizational Behavior. Third Edition. New Jersey: Prentice-Hall.

Barrick, M., \& Mount, M. (1991).The big five personality dimensions and job performance: A meta-analysis. Journal of Personality Psychology, 44, 1-26.

Barsoux, J.L. (1996). Why organizations need humor. European Management Journal, 14(5), 500-508.

Behpajouh, A., Jahangiri, M., \& Zahrakar, K. (2010). Training humor skills and reducing depression in patients with spinal cord injuries. Developmental Psychology, 23, 227-236.

Chamorro-Premuzic, T., \& Furnham, A. (2003). Personality predicts academic performance: evidence from two longitudinal studies on university students. Journal of Research in Personality, 37, 319-338.

Costa, P.T., \& McCrae, R.R. (1992). Revised NEO Personality Inventory (NEOPI-R) and NEO Five-factor Inventory (NEO- FFI): Professional manual. Odessa, FL: Psychological Assessment Resources.

Eliasi, M.H. (2009). Assessing the managers' personality characteristics and their relationship with their job performance, vitality and motivation. Quarterly of Inspection, 3(10), $68-88$.

Eysenck, H.J., \& Eysenck, S.B.G. (1975). Manual of the Eysenck Personality Questionnaire (adult and junior). Kent: UK: Hodder \& Stoughton.

Hamidifar, P. (2014). The relationship of humor with job performance and job burnout among staff at the Islamic Azad University of Sanandaj. MA thesis, Islamic Azad University, Sanandaj.

Khakpour, A. (2004). The relationship between personality traits and job performance (task and contextual) among junior school principals in the academic year 2003-2004 in Hamedan. MA thesis, Shahid Beheshti University, Tehran.

Martin, R.A. (2001). Humor, Laughter, and physical health: Methodological issues and research finding. Psychological Bulletin, 127(4), 504-519.

Maslach, C., Schaufeliand, W.B., \& Leiter, M.P. (2001). Job burnout. Annual Review of Psychology, 52, 397-422.

Moghimi, S.M., \& Ramezani, M. (2001). Organizational Psychology. Tehran: Rahdan Publication.

Naderian Jahromi, M., \& Amirhosseini, S.E. (2007). Examining the relationship between personality and demographic characteristics of sports managers with their job skills. Olympic Quarterly, 15(4), 105-114. 
Pouladi Reishahr, A., \& Golestane, S. (2008). Humor psychology, creativity, and mental health (first volume). Tehran: Nasl-e-No Publication.

Shabani Bahar, G.R., Amirtash, A.A., Mosharraf Javadi, B., Tondnevis, F. (2004). The relationship of personality traits with the effectiveness of physical education managers at universities across the country. Journal of Physical Education, 1(3), 12-30.

Williams, L.J., \& Anderson, S.E. (1991). Job satisfaction and organizational commitment as predicators of organizational citizenship and in-role behaviors. Journal of Management, 17(3), 601-617.

Yazdani, A. (2012). Investigate the relationship of personality traits, hardiness, and resilience in with academic success in students studying at Military Medical University. $\mathrm{PhD}$ thesis, School of Medicine, Military Medical University. 